\title{
Triberyllium Cluster Sandwich Complexes: A Density Functional Investigation
}

\author{
Robert W. Zoellner* \\ Department of Chemistry, Humboldt State University, One Harpst Street, Arcata, CA 95521-8299, USA
}

A R T I C L E IN F O

Article history:

Received 14 October 2015

Received in revised form 5 January 2016

Accepted 00 Month 2016

Available online 00 Month 2016

Keywords:

Inverse-sandwich complex

Sandwich complex

Triple-decker sandwich complex

Triberyllium cluster

Density functional

B3LYP

\section{A B S T R A C T}

Density functional computational results at the B3LYP/6-311+G** level of theory for triberyllium-benzene organometallic sandwich complexes are reported. These molecules are the first examples of triangular triberyllium clusters complexed to arene systems. An inverse sandwich complex is reported in which a benzene ring, distorted into a chair conformation, is bound between two eclipsed, triangular Be 3 clusters. In addition, a triple-decker complex is reported in which two eclipsed, triangular $\mathrm{Be}_{3}$ clusters are layered between a terminal benzene ring distorted into a boat conformation, a bridging benzene ring also distorted into a boat-like structure, and a terminal benzene ring with a chaise longue conformation. A simple sandwich complex containing a $\mathrm{Be}_{3}$ cluster bound between two distorted benzene rings, one in a boat conformation and the other in a chaise longue conformation, is also reported. The beryllium atoms are asymmetrically bound to the $\mathrm{C}_{6} \mathrm{H}_{6}$ rings in $\eta^{1}-, \eta^{2}-$, or $\eta^{3}-$ modes.

\footnotetext{
${ }^{*}$ Corresponding author. Tel.: +1 707826 3244; fax: +1 7078263279.

E-mail address: rwz7001@humboldt.edu (R.W. Zoellner).
} 


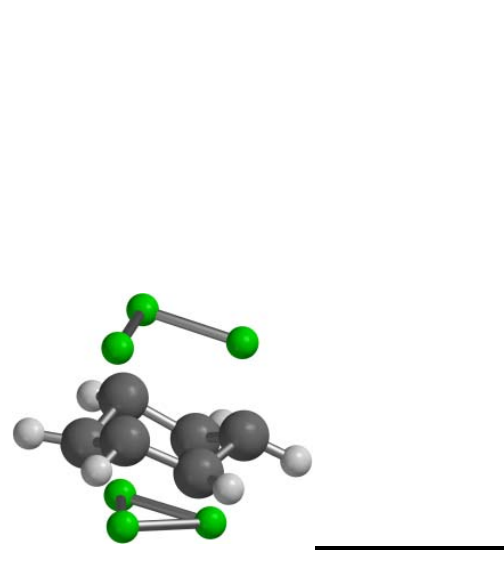

inverse sandwich

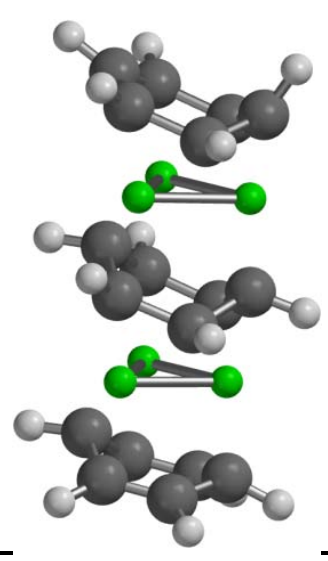

triple-decker sandwich

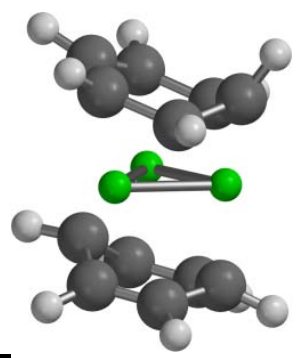

simple sandwich

S H O R T A B S T R A C T (for Table of Contents)

Organometallic complexes of triangular $\mathrm{Be}_{3}$ clusters with benzene rings have been investigated at the $\mathrm{B} 3 \mathrm{LYP} / 6-311+\mathrm{G}^{* *}$ level of density functional theory. An inverse sandwich complex, a triple-decker sandwich complex, and a simple sandwich complex were found to be stable at this level of theory.

\section{S Y N O P S I S}

- Structures and properties of triberyllium clusters bound to benzene rings are reported.

- An inverse, a triple-decker, and a simple sandwich complex of $\mathrm{Be}_{3}$ with benzene are described.

- The beryllium atoms adopt $\eta^{1}-, \eta^{2}$-, and $\eta^{3}$-bonding geometries to benzene in the complexes. 


\section{Introduction}

Recently [1], the structures and properties of the twelve so-called "beryllium-inserted benzenes" - heterocyclic molecules theoretically produced by successive insertions of beryllium atoms between adjacent carbon atoms in a benzene moiety - were determined at the B3LYP/6-311++G** level of density functional theory. Only three of the twelve possible monocyclic molecules were found to be stable ground state singlet molecules: beryllepin, 1,4diberyllocin, and 1,4,7-triberyllonin. The largest of the molecules that were investigated, the twelve-membered monocyclic system 1, was determined to be a ground state septet system, but also exhibited a low-lying pentet state [1].

The lack of a stable ground state singlet system for 1 led to the consideration of other potential structures for $\mathrm{C}_{6} \mathrm{Be}_{6} \mathrm{H}_{6}$ system, which culminated in the inverse sandwich systems depicted in Fig. 1. These unusual $\mathrm{C}_{6} \mathrm{Be}_{6} \mathrm{H}_{6}$ isomers contain a benzene ring sandwiched between two eclipsed (2e) or staggered (2s) triberyllium clusters. From that point, adding two capping benzene rings to form the triple-decker $\pi$-bound sandwich [2] compounds $\mathbf{3 e}$ and $\mathbf{3 s}$ was straightforward, as was envisioning the simpler bis(benzene)triberyllium( $(0)$ sandwich compound 4 (see Fig. 2).

Fig. 1. The conceptual deconstruction of $\mathbf{1}$ into inverse triberyllium sandwich complexes.

The main-group $\pi$-bound organometallic sandwich system 4 conforms to the "eighteenvalence-electron rule" for organometallic compounds: In 4, each benzene ring contributes six $\pi$ electrons to the system, while each beryllium atom contributes two valence electrons (from the filled $2 s$ orbitals on the neutral beryllium atoms), providing an overall eighteen valence electron count. As such, 4 is arguably an analog of the well-known [3] bis $\left(\eta^{6}\right.$-benzene $)$ chromium $(0)$ with the neutral chromium atom replaced by an uncharged triberyllium cluster. In addition, a "thirtyvalence-electron" rule applies to triple-decker complexes [4]. With six electrons contributed by each of the three benzene rings and six electrons contributed by each of the two triberyllium 
clusters, both $\mathbf{3 e}$ and $\mathbf{3 s}$ comply with this rule. Thus, at least with regard to simple valence electron counting schemes, $\mathbf{3 e}, \mathbf{3 s}$, and $\mathbf{4}$ may all be expected to be stable molecular systems [4].

Fig. 2. Hypothetical triberyllium sandwich complexes.

Beryllium sandwich compounds are far from unknown, despite the toxicity of beryllium and beryllium compounds [5]. Beryllocene, bis(cyclopentadienyl)beryllium(II), was first synthesized in 1959 [6]. Recently, a computational investigation at the BP86/TZ2P level of theory described related polymetallic cyclopentadienyl complexes in which a linear array of metal atoms, sandwiched between two cyclopentadienyl rings and arranged along the axis connecting the centroids of the cyclopentadienyl groups, was reported. The calculated results indicated that such complexes, in general, were unstable with respect to metal atom extrusion. The exceptions were the linear beryllium systems, $\left(\eta^{5}-\mathrm{C}_{5} \mathrm{H}_{5}\right)_{2} \mathrm{Be}_{n}, n=2-5$, in which all molecules were calculated to be stable and resistant to the extrusion of beryllium atoms [7]. (No triangular triberyllium systems were investigated.) Similar calculations have been carried out at the B3LYP/cc-PVDZ and BP86/6-311G** levels of theory for the open sandwich $\left(\eta^{5}-\mathrm{C}_{5} \mathrm{H}_{7}\right)-\mathrm{Be}_{2}-\left(\eta^{5}-\mathrm{C}_{5} \mathrm{H}_{7}\right)$ complexes. These theoretical molecules contain a $\mathrm{Be}-\mathrm{Be}$ moiety approximately perpendicular to the planes of the ligands in which each $\eta^{5}$-pentadienyl ligand is bound to only one beryllium atom. The calculated $\mathrm{Be}-\mathrm{Be}$ distance was $208.1 \mathrm{pm}$ with $\mathrm{B} 3 \mathrm{LYP} / \mathrm{cc}-\mathrm{PVDZ}$ and $207.6 \mathrm{pm}$ with BP86/6-311G** [8].

Pentafulvene complexes of alkaline earth metals, including beryllium, have also been the subject of computational examinations at the B3LYP/6-311++G(d,p) level of theory. Unlike the calculated structures of the bis- $\eta^{5}$-pentafulvene complexes of $\mathrm{Mg}, \mathrm{Ca}, \mathrm{Sr}$, and $\mathrm{Ba}$, the beryllium complexes were better described as $\eta^{1}, \eta^{5}$-systems [9]. Such $\eta^{1}, \eta^{5}$-structures are similar to the accepted structure of beryllocene, which, although highly fluxional $[10,11]$, contains both $\eta^{5}$ and $\eta^{1}$-bound $\mathrm{C}_{5} \mathrm{H}_{5}$ rings [12-15]; computational reports also support an $\eta^{1}, \eta^{5}$-description of the bonding in beryllocene [16-18].

Reports of beryllium sandwich compounds in which the organic ligands are $\pi$-bound arenes are unfortunately nearly non-existent. No experimental syntheses of arene-beryllium sandwich compounds have been reported, and the only report of isomers of bis(benzene)beryllium( 0 ) is a computational investigation using the semiempirical MNDO method [19].

There are some additional reports in which density functional investigations of molecular systems containing beryllium are detailed. Among these, the beryllium(II) carbonate complexes 
of the noble gases $\mathrm{He}, \mathrm{Ne}, \mathrm{Ar}, \mathrm{Kr}$, and $\mathrm{Xe}$ have been the subject of computational studies that were substantiated by experiments in low temperature neon matrices [20]. The square pyramidal cluster $\mathrm{BeCN}_{2} \mathrm{O}$ and other alkali and alkaline earth metal analogs have been studied at the B3LYP/6-311+G* level of theory; based on nucleus independent chemical shift (NICS) data, the $\mathrm{CN}_{2} \mathrm{O}^{2-}$ anion exhibited $\pi$-aromaticity [21]. Beryllium(II) complexes of $N, O$-chelate ligands have been investigated using time-dependent density functional theory [22], and the structures of cyclic polyalanine peptide complexes of beryllium(II) have also been determined [23].

Extensive computational work has also been reported on systems containing beryllium bonds $[24,25]$. The beryllium bond - a Lewis acid-Lewis base interaction between a divalent beryllium species, BeXY (the Lewis acid), and many different types of Lewis bases - has been shown theoretically to enhance the properties of many systems through cooperativity. These cooperative interactions can occur, for example, with $\pi$-systems [26] and with aromatic systems such as fullerenes, nanotubes, and graphene as modeled by naphthalene and pyrene [27].

Herein are reported the density functional computational results for the triberyllium clustercontaining organometallic sandwich molecules 3e, 3s, and 4 at the B3LYP/6-311+G** level of theory. In addition, comparative results at the same level of theory for the inverse sandwich complexes $2 \mathbf{e}$ and $\mathbf{2 s}$ are included.

\section{Computational methods}

The structures and properties of all singlet molecules were determined at the restricted B3LYP/6-311+G** density functional level of theory using the Spartan '14 program package [28]. Multiple initial trial geometries were investigated for each system investigated. In all cases, vibrational frequencies were calculated for the optimized geometry of each molecule so as to assure the existence of a stable minimum on the potential energy surface. In those cases in which one or more imaginary vibrational frequencies were calculated to be present, the structures of the molecules were adjusted, based on the atom displacements of the imaginary frequencies, and then re-optimized in an attempt to locate a stable minimum on the potential energy surface for that molecule.

\section{Results and discussion}

\subsection{Inverse sandwich complexes}

Unsurprisingly, no computational support could be generated for the rearrangement of $\mathbf{1}$ to $\mathbf{2 e}$ or to $\mathbf{2 s}$ as depicted in Fig. 1. This failure may be due to the lack of a stable singlet form of $\mathbf{1}$ from which to begin the rearrangement process to the singlet inverse sandwich complexes or to the inability to identify a stable septet structure of $2 \mathbf{e}$ or $\mathbf{2 s}$ as the termination point of the rearrangement. In addition, $\mathbf{2 s}$ could not be successfully optimized under any circumstances. Despite the use of many different staggered initial trial geometries, the optimizations failed to converge, converged with multiple imaginary frequencies, resulted in the rearrangement of $2 \mathbf{s}$ to $\mathbf{2 e}$, or did not exhibit a stable wave function. In optimizations that resulted with imaginary frequencies, the atomic movements involved in the imaginary frequencies often indicated a 
reaction pathway that, after atomic rearrangement and re-optimization, led to the conversion of $2 \mathrm{~s}$ to $2 \mathrm{e}$.

On the other hand, $\mathbf{2 e}$ was able to be optimized from eclipsed initial trial geometries as a singlet molecule in which the $\mathrm{C}_{6} \mathrm{H}_{6}$ layer adopted a chair shape (Fig. 3). When boat-shaped $\mathrm{C}_{6} \mathrm{H}_{6}$ geometries were investigated, no optimized geometry could be identified for which a stable wave function was found to exist. The structure of $\mathbf{2 e}$ was found to deviate, however, from the idealized sketch in Fig. 1.

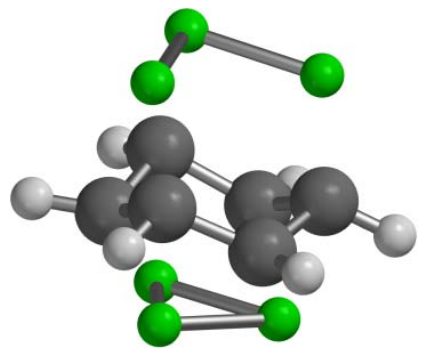

Fig. 3. The inverse sandwich complex 2e. The $\mathrm{Be}-\mathrm{C}$ distances noted on the right-hand sketch are in pm; no Be-C contacts greater than $200 \mathrm{pm}$ have been included. Hydrogen atoms were omitted from the sketch for purposes of clarity.

In 2e, one of the triangular triberyllium moieties remained fully bonded in the optimized structure while the other opened into a $\vee$-shaped system. The $\mathrm{Be}-\mathrm{Be}$ bond lengths in the triangular $\mathrm{Be}_{3}$ portion of the molecule were 197.3, 197.2, and $195.6 \mathrm{pm}$, while in the $\vee$-shaped $\mathrm{Be}_{3}$ portion, the distances were 200.9 and $201.3 \mathrm{pm}$ for the bound $\mathrm{Be}-\mathrm{Be}$ distances, and 279.0 $\mathrm{pm}$ for the $\mathrm{Be}-\mathrm{Be}$ distance on the open end of the $\mathrm{v}$. In metallic beryllium, the $\mathrm{Be}-\mathrm{Be}$ distance is $224 \mathrm{pm}$, based on a metallic radius [29] of $112 \mathrm{pm}$; the atomic radius is reported to be 124.4 $\mathrm{pm}[30]$. The open edge of the $\vee$ is directly above the shortest of the $\mathrm{Be}-\mathrm{Be}$ distances in the triangular $\mathrm{Be}_{3}$ portion of the molecule.

The $\mathrm{C}_{6} \mathrm{H}_{6}$ moiety in $\mathbf{2 e}$ is highly distorted from planarity into a chair configuration with $\mathrm{C}-\mathrm{C}$ bond lengths ranging from $155.4 \mathrm{pm}$ to $157.5 \mathrm{pm}$. These distances are generally indicative of $\mathrm{C}-$ $\mathrm{C}$ single bonds [31]. The stylized sketch in Fig. 3 details the relevant $\mathrm{Be}-\mathrm{C}$ distances in $\mathbf{2 e}$.

Note that the beryllium atoms in the $\vee$-shaped $\mathrm{Be}_{3}$ portion of the molecule are primarily bound to single carbon atoms in a " $1,3,5$ "-arrangement reminiscent of the structure of a tri-substituted cyclohexane, while each of the beryllium atoms in the triangular $\mathrm{Be}_{3}$ portion of the molecule is bound to three adjacent carbon atoms in a fashion similar to that of allyl bonding. While allyl systems with bulky substituents tend to favor a $\sigma$-bonding mode to beryllium, both $\sigma$ - and $\pi$ bonding to allyl are possible for beryllium [32]. Generally, $\pi$-bound allyl groups are energetically favored in the absence of basic donor ligands [32]. The $\mathrm{Be}-\mathrm{C}$ distances (Fig. 3) range from $174.2 \mathrm{pm}$ to $184.6 \mathrm{pm}$; these distances compare well with Be-aryl [33-35] and Becarbene distances $[33,36,37]$.

\subsection{Triple-decker sandwich complexes}

The optimization of $\mathbf{2 e}$, with the $\mathrm{C}_{6} \mathrm{H}_{6}$ moiety adopting a chair configuration, indicated that the triple-decker complexes $\mathbf{3 e}$ and $\mathbf{3 s}$ might also adopt such a configuration for (at least) the 
central layer of the sandwich. However, the triple-decker complex 3e was found to optimize smoothly from a variety of initial trial geometries (including planar, chair, and boat configurations of the $\mathrm{C}_{6} \mathrm{H}_{6}$ layers) to the optimized geometry depicted in Fig. 4. In 3e, one of the terminal $\mathrm{C}_{6} \mathrm{H}_{6}$ layers and the bridging $\mathrm{C}_{6} \mathrm{H}_{6}$ layer adopted boat configurations, while the remaining terminal $\mathrm{C}_{6} \mathrm{H}_{6}$ layer adopted a chaise longue shape. Despite multiple computational attempts beginning from different initial trial geometries, no stable structure - whether with boat, chair, or chaise-lounge configurations - could be identified for the triple decker sandwich complex 3s. (In all cases investigated, calculations beginning from staggered initial trial geometries failed to optimize, optimized with multiple imaginary frequencies, rearranged to the 3e geometry, or did not exhibit a stable wave function.) In optimizations of $\mathbf{3 s}$ that resulted in multiple imaginary frequencies, the atomic movements involved in the imaginary frequencies again indicated a reaction pathway that, after atomic rearrangement and re-optimization, led to the conversion of $\mathbf{3 s}$ to $3 \mathbf{e}$. In no case did a $\mathrm{C}_{6} \mathrm{H}_{6}$ layer remain planar after optimization.

The extent of distortion of the $\mathrm{C}_{6} \mathrm{H}_{6}$ layers in $\mathbf{3 e}$ can be estimated by comparing the "fold" angles of the three carbon atoms at the "prow" and "stern" of the boat with respect to the four carbon atoms forming the "bottom" of the boat. For the terminal $\mathrm{C}_{6} \mathrm{H}_{6}$ layer with the boat configuration, given the orientation of the molecule in Fig. 4, the stern to the left adopts a fold angle of $\sim 37^{\circ}$ up, while the prow to the right is folded up by $\sim 28^{\circ}$ (where a fold angle of $0^{\circ}$ indicates a flat system). The equivalent angles for the central $\mathrm{C}_{6} \mathrm{H}_{6}$ layer are $\sim 33^{\circ}$ up on the left and $\sim 52^{\circ}$ up on the right. Finally, the terminal chaise longue layer exhibits folds of $\sim 15^{\circ}$ up on the left and $\sim 54^{\circ}$ up on the right. (For comparison, the fold angles in $2 \mathrm{e}$ are $\sim 59^{\circ}$ down to the left and up to the right.)

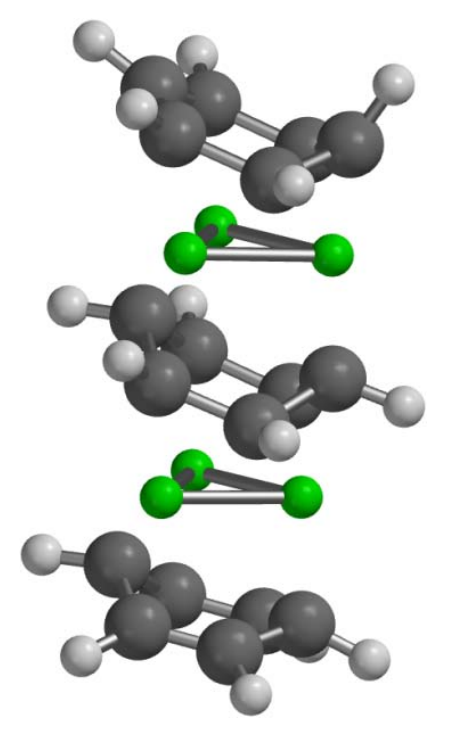

Fig. 4. The triple-decker sandwich complex 3e. The Be-C distances noted on the right-hand sketch are in pm; no Be-C contacts greater than $200 \mathrm{pm}$ have been included. Hydrogen atoms have been omitted from the sketch for purposes of clarity. The $\mathrm{C}-\mathrm{C}$ bonds in this molecule shorter than 150 $\mathrm{pm}$ are depicted with hatched lines, while those shorter than $140 \mathrm{pm}$ are depicted as double lines.

Beyond the significant distortions of the three benzene rings in the structure, the $\mathrm{Be}_{3}$ units in $\mathbf{3 e}$ - unlike the $\vee$-shaped $\mathrm{Be}_{3}$ layer in $\mathbf{2 e}$ - remain as triangular systems with no "open" edges. 
Bond distances in the $\mathrm{Be}_{3}$ clusters, however, are longer than in $\mathbf{2 e}$, and range from $211.2 \mathrm{pm}$ to $220.0 \mathrm{pm}$. These distances are still somewhat shorter than the $\mathrm{Be}-\mathrm{Be}$ distances in metallic beryllium $[29,30]$.

The $\mathrm{C}-\mathrm{C}$ distances in the central $\mathrm{C}_{6} \mathrm{H}_{6}$ layer of $3 \mathbf{e}$ range from $154.7 \mathrm{pm}$ to $156.9 \mathrm{pm}$; these distances are again indicative of $\mathrm{C}-\mathrm{C}$ single bonds [31]. However, bond lengths in the terminal $\mathrm{C}_{6} \mathrm{H}_{6}$ layers indicate that some multiple bonding has remained in these terminal $\mathrm{C}_{6} \mathrm{H}_{6}$ rings. In the lower, boat-shaped terminal $\mathrm{C}_{6} \mathrm{H}_{6}$ layer, two $\mathrm{C}-\mathrm{C}$ bonds are noted at a distance of $136.6 \mathrm{pm}$, highly indicative of a carbon-carbon double bond [31], while two other bonds exhibit an intermediate distance between a double and a single bond at $147.8 \mathrm{pm}$ and $147.9 \mathrm{pm}$. The remaining two bonds exhibit a distance of $152.2 \mathrm{pm}$ and $152.3 \mathrm{pm}$. Further, in the upper, chaise longue-shaped $\mathrm{C}_{6} \mathrm{H}_{6}$ layer, while no bonds are short enough to be considered double bonds, two bonds exhibit distances of $140.8 \mathrm{pm}$ with the remainder ranging from $151.7 \mathrm{pm}$ to $158.6 \mathrm{pm}$. The shorter bonds in each ring are associated with carbon atoms to which either no beryllium atoms are bound or to which only one beryllium atom is bound.

The $\mathrm{Be}-\mathrm{C}$ distances in $\mathbf{3 e}$ range from $171.3 \mathrm{pm}$ to $191.3 \mathrm{pm}$, which is a slightly wider range than that observed for 2e. While these distances again appear to compare well with Be-aryl [33$35]$ and Be-carbene distances [33,36,37] the longer distances (in the 190 pm range) may be only weakly bonding or may be the coincidental result of the molecular geometry.

\subsection{Simple sandwich complex 4}

The triberyllium sandwich complex 4 is depicted in Fig. 5. Perhaps the most obvious feature of the structure of $\mathbf{4}$ is the similarity of the distortions of the $\mathrm{C}_{6} \mathrm{H}_{6}$ layers in $\mathbf{4}$ to those of the terminal $\mathrm{C}_{6} \mathrm{H}_{6}$ layers in 3e: The terminal distorted boat-shaped $\mathrm{C}_{6} \mathrm{H}_{6}$ ring and the terminal chaise longue-shaped $\mathrm{C}_{6} \mathrm{H}_{6}$ ring noted in $\mathbf{3 e}$ are fundamentally reproduced in $\mathbf{4}$, albeit sandwiching only one $\mathrm{Be}_{3}$ layer. The fold angles of the boat layer are $\sim 38^{\circ}$ up on the left and $\sim 26^{\circ}$ up on the right, while for the chaise longue, the angles are $\sim 11^{\circ}$ up on the left and $\sim 42^{\circ}$ up on the right. These values are very similar to the fold angles of the terminal $\mathrm{C}_{6} \mathrm{H}_{6}$ layers of $3 \mathbf{e}$. The $\mathrm{Be}_{3}$ cluster in 4 exhibits two Be-Be distances of $212.6 \mathrm{pm}$ and one distance of $217.8 \mathrm{pm}$.

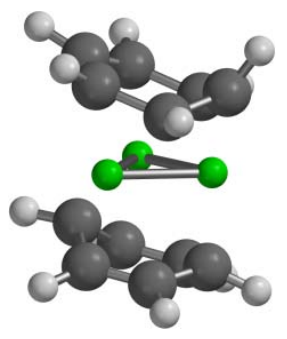

Fig 5. Bis(benzene)triberyllium(0), 4. The $\mathrm{Be}-\mathrm{C}$ distances noted on the right-hand sketch are in $\mathrm{pm}$; no $\mathrm{Be}-\mathrm{C}$ contacts greater than $200 \mathrm{pm}$ have been included. Hydrogen atoms have been omitted from the sketch for purposes of clarity. The $\mathrm{C}-\mathrm{C}$ bonds in this molecule shorter than $150 \mathrm{pm}$ are depicted with hatched lines, while those shorter than $140 \mathrm{pm}$ are depicted as double lines. 
The $\mathrm{Be}-\mathrm{C}$ bonds to the terminal $\mathrm{C}_{6} \mathrm{H}_{6}$ layers and the $\mathrm{C}-\mathrm{C}$ bond distances within the terminal $\mathrm{C}_{6} \mathrm{H}_{6}$ layers in $3 \mathbf{e}$ are very similar to those in $\mathbf{4}$. Both molecules exhibit $\mathrm{C}-\mathrm{C}$ distances indicative of single, intermediate, and double bonds. The similarities in structure of $\mathbf{3 e}$ and $\mathbf{4}$ may indicate the potential for oligomers in which triberyllium clusters are sandwiched between boat-shaped benzene rings. Both molecules are asymmetric with large dipole moments: For 4, the calculated dipole moment is $3.20 \mathrm{D}$, while for $3 \mathrm{e}$, the calculated dipole moment is $7.67 \mathrm{D}$. In both cases, the dipole moment vector is parallel with the molecular axis perpendicular to the triberyllium cluster plane with the negative end of the vector pointing toward the chaise longue end of the molecule.

\subsection{Bonding and bond orders}

The bonding in bis $\left(\eta^{6}\right.$-benzene)chromium( 0$)$, as determined at the SCF MS X $\alpha$ level of theory [38] and more recently at the BPW91/TZVP level of theory [39] may be most easily and simply described in terms of covalent interactions between the $\pi$ and $\pi^{*}$ ligand orbitals of the $\mathrm{C}_{6} \mathrm{H}_{6}$ groups and the $3 d, 4 s$, and $4 p$ orbitals on the chromium center. In a similar fashion, the bonding in bis(benzene)triberyllium $(0)$ - as indicated by the molecular orbitals which involve significant Be-C interactions (Fig. S1 in the Supplementary Data section) - can be described in terms of covalent interactions between the $\pi$ and $\pi^{*}$ ligand orbitals of the $\mathrm{C}_{6} \mathrm{H}_{6}$ layers and the $2 s$ and $2 p$ orbitals of the triberyllium cluster.

The structures of $\mathbf{3 e}$ and $\mathbf{4}$ indicate that the beryllium atoms exhibit $\eta^{1}-, \eta^{2}$-, and $\eta^{3}$-modes of bonding to the carbon atoms of the $\mathrm{C}_{6} \mathrm{H}_{6}$ rings, with some carbon atoms in the terminal rings not involved in bonding to the beryllium atoms. The bridging boat-conformation $\mathrm{C}_{6} \mathrm{H}_{6}$ ring of $\mathbf{3 e}$ and the chair-conformation ring of $2 \mathrm{e}$ are the only $\mathrm{C}_{6} \mathrm{H}_{6}$ rings in which all carbon atoms bond to at least one beryllium atom.

\subsection{Potential synthesis of the stable complexes}

Could 3a and/or $\mathbf{4}$ be synthesized? The metal vapor synthesis technique [40] may be the most direct method, as the low-temperature co-deposition of beryllium vapor (despite the toxicity issues) with benzene or another arene might realistically result in the preparation of 4 , 3e, or other "higher-decker" polymer-like systems. The experimental reduction potential of benzene is $-3.42 \mathrm{~V} v s$. SCE when measured in dry dimethoxyethane with tetrabutylammonium hexafluorophosphate as the supporting electrolyte [41]. This value converts to $-3.18 \mathrm{~V} v s$. SHE. Coupling this value with the standard reduction potential [42] for $\mathrm{Be}^{2+}$ of $-1.85 \mathrm{~V}$, the metal vapor synthesis reaction is suggested to occur without decomposition reactions caused by arene reduction or beryllium oxidation.

\section{Conclusion}

Benzene complexes of triberyllium clusters have been shown to be stable systems, as exemplified by the triple decker sandwich complex $\mathbf{3 e}$ and the simple sandwich complex 4 . These complexes appear to be realistic synthetic targets. In addition, the inverse sandwich 
complex 2e was shown to exhibit a stable minimum optimized structure, although $\mathbf{2 e}$ is probably not experimentally realizable.

\section{Acknowledgements}

The National Science Foundation's Course, Curriculum, and Laboratory Improvement Program, Adaptation and Implementation Section (NSF-9950344), is acknowledged for generous support for the initial purchase of computers and computational chemistry software. Matching funds and additional and continuing support have been received at various times from the Humboldt State University Department of Chemistry, the College of Natural Resources and Sciences, the Office for Research and Graduate Studies, the Office of the Vice-President for Academic Affairs, and the Office of the President, as well as from the Humboldt State University Sponsored Programs Foundation. Initially, the inspiration for this project came from a suggestion by Dr. Jonathan P. Goss of the School of Electrical and Electronic Engineering, Newcastle University, U.K.

\section{References}

[1] A. A. Tabares, E. L. Waters, R. W. Zoellner, Heteroatom Chem. (2015) doi: 10.1002/hc.21298.

[2] J. W. Lauher, M. Elian, R. H. Summerville, R. Hoffmann, J. Am. Chem. Soc. 98 (1976) 3219-3224.

[3] (a) D. Seyferth, Organometallics 21 (2002) 1520-1530. (b) D. Seyferth, Organometallics 21 (2002) 2800-2820.

[4] W. Siebert, Pure Appl. Chem. 60 (1988) 1345-1348.

[5] R. M. Bruce, M. Odin, Concise International Chemical Assessment Document 32: Beryllium and Beryllium Compounds, World Health Organization, Geneva, (2001).

[6] E. O. Fischer, H. P. Hofmann, Chem. Ber. 92 (1959) 482-486.

[7] A. Velazquez, I. Fernández, G. Frenking, G. Merino, Organometallics 26 (2007) 47314736.

[8] J.-H. Sheu, M.-D. Su, J. Organomet. Chem. 696 (2011) 1221-1227.

[9] W. P. Oziminski, J. Organomet. Chem. $708-709$ (2012) 10-17.

[10] K. W. Nugent, J. K. Beattie, L. D. Field, J. Phys. Chem. 93 (1989) 5371-5377.

[11] P. Margl, K. Schwarz, P. E. Blöchl, J. Am. Chem. Soc. 116 (1994) 11177-11178.

[12] J. K. Beattie, K. W. Nugent, Inorg. Chim. Acta 198-200 (1992) 309-318.

[13] (a) A. Almenningen, O. Bastiansen, A. Haaland, J. Chem. Phys. 40 (1964) 3434-3437. (b) A. Haaland, Acta Chem. Scand. 22 (1968) 3030-3032. (c) D. A. Drew, A. Haaland, Acta Cryst. B28 (1972) 3671. (d) A. Almenningen, A. Haaland, J. Lusztyk, J. Organomet. Chem. 170 (1979) 271-284.

[14] K. W. Nugent, J. K. Beattie, T. W. Hambley, M. R. Snow, Aust. J. Chem. 37 (1984) 16011606. 
[15] (a) C.-H. Wong, T.-Y. Lee, K.-J. Chao, S. Lee, Acta Cryst. B28 (1972) 1662-1665. (b) C. Wong, T. Y. Lee, T. J. Lee, T. W. Chang, C. S. Liu, Inorg. Nucl. Chem. Lett. 9 (1973) 667-673.

[16] N.-S. Chiu, L. Schäfer, J. Am. Chem. Soc. 100 (1978) 2604-2607.

[17] J. Demuynck, M. M. Rohmer, Chem. Phys. Lett. 54 (1978) 567-570.

[18] R. Gleiter, M. C. Böhm, A. Haaland, R. Johansen, J. Lusztyk, J. Organomet. Chem. 170 (1979) 285-292.

[19] J. R. Bews, C. Glidewell, J. Organomet. Chem. 219 (1981) 279-293.

[20] Q. Zhang, M. Chen, M. Zhou, D. M. Andrada, G. Frenking, J. Phys. Chem. A 119 (2015) 2443-2552.

[21] B. Jin, Q. Jin, W. G. Xu, Comp. Theor. Chem. 966 (2011) 9-13.

[22] Y.-P. Tong, S.-L. Zheng, X.-M. Chen, Inorg. Chem. 44 (2005) 4270-4275.

[23] H. Song, G. Liu, Y. Yang, H. Wei, Y. Jian, J. Chem. Chem. Eng. 5 (2011) 250-254.

[24] M. Yáñez, P. Sanz, O. Mó, I. Alkorta, J. Elguero, J. Chem. Theory Comput. 5 (2009) 2763-2771.

[25] I. Alkorta, J. Elguero, M. Yáñez, O. Mó, Phys. Chem. Chem. Phys. 16 (2014) 4305-4312.

[26] E. Fernández Villanueva, O. Mó, M. Yáñez, Phys. Chem. Chem. Phys. 16 (2014) 1753117536.

[27] M. Marín-Luna, I. Alkorta, J. Elguero, O. Mó, M. Yáñez, ChemPhysChem 16 (2015) 2680-2686.

[28] Spartan '14, version 1.1.4, Wavefunction, Inc., 18401 Von Karman Avenue, Suite 370, Irvine, CA 92612.

[29] N. N. Greenwood, A. Earnshaw, Chemistry of the Elements, Pergamon Press, Oxford, (1984) pg. 122.

[30] J. Hafner, H. Eschrig, Phys. Stat. Sol. B 72 (1975) 179-188.

[31] T. R. Gilbert, R. V. Kirss, N. Foster, G. Davies, Chemistry: The Science in Context, Fourth Edition, W. W. Norton and Company, New York, (2015) pg. 404.

[32] S. C. Chmely, T. P. Hanusa, W. W. Brennessel, Angew. Chem. Int. Ed. 49 (2010) 58705874.

[33] J. Gottfriedsen, S. Blaurock, Organometalics 25 (3006) 3784-3786.

[34] K. Ruhlandt-Senge, R. A. Bartlett, M. M. Olmstead, P. P. Power, Inorg. Chem. 32 (1993) 1724-1728.

[35] M. Niemeyer, P. P. Power, Synthesis, Inorg. Chem. 36 (1997) 4688-4696.

[36] W. A. Herrmann, O. Runte, G. Artus, J. Organomet. Chem. 501 (1995) C1-C4.

[37] W. A. Herrmann, C. Köcher, Angew. Chem. Int. Ed. Engl. 36 (1997) 2162-2187.

[38] J. Weber, E. P. Kundig, A. Goursot, E. Penigault, Can. J. Chem. 63 (1985) 1734-1740.

[39] S. Yu. Ketkov, H. L. Selzle, Zeit. Phys. Chem. 221 (2007) 597-607.

[40] K. J. Klabunde, G. Cardenas-Trivino, Metal atom/vapour approaches to active metal clusters/particles, A. Fürstner, ed., Active Metals: Preparation, Characterization, Applications, Wiley-VCH, Weinheim, doi: 10.1002/9783527615179, (1995) ch. 6.

[41] J. Mortensen, J. Heinze, Angew. Chem. Int. Ed. Engl. 23 (1984) 84.

[42] D. R. Lide, ed., CRC Handbook of Chemistry and Physics, Eighty-fifth Edition, CRC Press, Boca Raton, (2004) pp. 8-23. 